\title{
ACERCAMIENTO A LAS EMOCIONES MEDIEVALES: DOS CARTAS DE HILDEGARD DE BINGEN (1098-1179) ${ }^{1}$
}

\author{
María Eugenia Góngora \\ Universidad de Chile \\ egongora@u.uchile.cl
}

\section{RESUMEN / ABSTRACT}

En este artículo se estudian dos cartas de la religiosa alemana Hildegard de Bingen, intentando dar cuenta de la 'historicidad de las emociones' de manera muy acotada y en el marco de la escritura epistolar monástica europea del siglo XII. La primera carta, dirigida a la joven religiosa Ricardis von Stade y escrita en 1151, y la segunda, escrita hacia 1175, fue la respuesta que Hildegard envió a un joven monje, Guibert de Gembloux, con respecto a la naturaleza de sus visiones. En el comentario de ambos textos se considera la especificidad de las emociones que se manifiestan en esas cartas destinadas a ser leídas por sus destinatarios y también por comunidades monásticas y religiosas más amplias. Es importante reconocer que nuestra lectura actual está determinada por ciertos supuestos que, en alguna medida, nos distancian de manera significativa de la lectura que pudieron hacer los destinatarios contemporáneos a la escritura de cartas medievales similares a las aquí consideradas.

Palabras clave: Hildegard de Bingen, epistolario, historicidad de las emociones, Ricardis de Stade, Guibert de Gembloux.

The aim of this paper is to account for the 'historicity of emotions'by reading and commenting two letters by the German nun Hildegard of Bingen as examples of 12th century epistolary monastic writing. The first letter, written in 1151, was addressed to the young nun Richardis of Staden. The second one, written in 1175, was Hildegard's answer to the young monk Guibert

1 Una primera versión de este trabajo fue leída en el marco del Encuentro sobre las Emociones, Facultad de Filosofía y Humanidades de la Universidad de Chile, realizado en abril de 2011. 
of Gembloux concerning the nature of her visions. In the commentary of these texts, addressed not only to their nominal addressees, but also to a wider monastic community, I explore the specific emotions which Hildegard elaborated and expressed in writing. It is important to acknowledge that today's reading of these letters is determined by perspectives which widely differ from their medieval reception.

KEY WORDs: Hildegard de Bingen, epistolary, historicity of emotions, Richardis of Staden, Guibert of Gembloux.

Affectus, qui passio est, desinit esse passio simulatque eius claram et distinctam formamus ideam (Spinoza, Ethica V 3, 6-7) ${ }^{2}$

\section{CONSIDERACIONES PRELIMINARES SOBRE LAS EMOCIONES EN LA EDAD MEDIA EUROPEA}

La complejidad de las distinciones posibles entre pasión y emoción ha dado lugar a discusiones sobre las que se ha argumentado y reflexionado abundantemente desde la filosofía. Alimentado directa o indirectamente por las lecturas de Platón y de Aristóteles ${ }^{3}$, pasando por Cicerón y los estoicos, por Orígenes, por Galeno y las teorías médicas, el pensamiento medieval sobre el affectus $^{4}$, que podemos traducir básicamente como emoción, así como sobre los 'primeros movimientos', presentes en las discusiones de las Escuelas (desde Abelardo a Tomás de Aquinas y Scotus Eriugena), se nutrió también de los aportes que San Agustín -sobre todo en La Ciudad de Dios y las Confesiones- y el papa Gregorio Magno hicieron a la espiritualidad

2 Baruch Spinoza, Ethica V, 3: "El affectus (la emoción), que constituye sufrimiento, deja de serlo en el mismo momento en que nos formamos una idea clara y precisa del mismo" (mi traducción revisada de la de Vidal Peña en Baruch Spinoza, Etica demostrada según el orden geométrico, Vidal Peña, ed., Madrid: Editora Nacional/Ediciones Orbis, 1980, p. 252).

3 El uso platónico y luego aristotélico de pathos (si bien Aristóteles utilizó sobre todo el pl. pathé) será decisivo en las discusiones posteriores sobre pasiones y emociones. Ver Barbara H. Rosenwein, Emotional Communities in the early Middle Ages. Ithaca \& London: Cornell University Press 2006, esp. el capítulo “The Ancient Legacy", y los apartados dedicados a Platón y a Aristóteles y su pensamiento sobre las emociones, pp. 32-36.

$4 \quad$ Se puede traducir el affectus, en términos muy generales, como una moción que afecta al ánimo y a las diversas facultades y capacidades humanas. 
monástica ${ }^{5}$. Las discusiones sobre el carácter involuntario de los 'primeros movimientos', de las emociones y sus efectos, así como sobre el valor de la moderación y de la apatheia serán por cierto muy importantes en esta tradición ${ }^{6}$.

Creo que es necesario, por lo mismo, subrayar la historicidad de las emociones; los más recientes estudios sobre las emociones en comunidades contemporáneas permiten confirmar, desde distintas perspectivas disciplinarias, la variedad de las manifestaciones de aquellas emociones que han sido pensadas desde la filosofia ${ }^{7}$. En el contexto específicamente medieval europeo, es posible afirmar, como lo ha hecho la medievalista Barbara Rosenwein ${ }^{8}$, que históricamente

5 Para un estudio de las emociones en la filosofía antigua y medieval, ver Simo Knuuttila 2004. El pensamiento estoico alimentó en buena medida las discusiones medievales; por lo mismo, vale la pena recordar que para autores como Diógenes y Andronicus, las emociones se pueden calificar como positivas (placer y apetito, deseo) y negativas (tristeza y temor) de acuerdo al tiempo en el que se experimentan: placer y dolor en el presente; deseo y temor en vistas al futuro (Knuuttila 52).

6 Para un importante estudio multidisciplinario sobre las emociones en la Edad Media, ver Le sujet des émotions au Moyen Âge, Paris: Beauchesne, 2008, dirigido por Piroska Nagy y Damien Boquet; en relación a las discusiones filosóficas medievales, ver en este volumen los artículos de Damien Boquet, "Des racines de l'émotion. Les préaffects et le tournant anthropologique du XIIème siècle", pp. 163- 186, y de Irène Rosier-Catach, "Discussions médiévales sur l'expression des affects", pp. 201-223.

Las bases de muchos de los trabajos sobre la afectividad y las emociones y sus manifestaciones en la Edad Media se encuentran, sin duda, en el pensamiento de historiadores como Lucien Febvre, Marc Bloch, Johan Huizinga y, en menor medida, del sociólogo Norbert Elias. Una discusión en torno a las perspectivas teóricas sobre la sensibilidad medieval está en el importante artículo de Febvre en el que llama a realizar una historia de las sensibilidades y de las emociones, "Comment reconstituer la vie affective d'autrefois? La sensibilité et l'histoire", publicado en los Annales d'Histoire économique et sociale 3, de 1941 y recogido en su libro Combats pour l'Histoire, de 1952. En ese texto critica la posición de Huizinga sobre "el tono de la vida", o el "áspero sabor de la vida" durante la Edad Media europea; éste es el título del primer capítulo de El otoño de la Edad Media (1919), del historiador holandés, y ha marcado sin duda a los lectores de esa obra clásica por décadas. Por otra parte, me parecen particularmente útiles los trabajos más recientes de autores como Jean-Claude Schmitt, Piroska Nagy, Horst Wenzel y Gerd Althoff, entre muchos otros, sobre la función social y la ritualidad de gestos y de emociones en la Europa medieval.

Existe asimismo una muy abundante bibliografía sobre las devociones medievales, cuya atención a las emociones es también, por cierto, una fuente de información sobre estos fenómenos y sobre su historicidad.

$8 \quad$ Ver en particular el artículo de Barbara Rosenwein: "Worrying about Emotions in History", pp. 281-245. Para una actualización útil de la historia del estudio de las emociones desde la antropología, la psicología y los estudios cognitivos, así como desde la historia y los estudios literarios, ver también Barbara Rosenwein, "Problems and Methods in the History of 
existieron -y existen también hoy día- 'comunidades emocionales' ${ }^{9}$, como las ha denominado esta autora. Propone que las personas viven -y han vivido- en 'comunidades emocionales', cada una de las cuales posee sus propias normas de evaluación -y devaluación- emocional y de expresión de las mismas. Por otra parte, podemos afirmar que esas comunidades se han cohesionado en torno a emociones e identidades que las trascienden; el hecho de que en un momento histórico y en una misma sociedad puedan coexistir 'comunidades emocionales' de diversas características, muchas veces contradictorias y hasta 'adversarias', debe llamarnos la atención en el sentido de que una sociedad no 'produce' necesariamente emociones totalmente hegemónicas, aunque exista un discurso frente al cual no pareciera posible siquiera el surgimiento de voces divergentes. Las emociones ligadas más directamente a las conquistas territoriales, a la lengua, la política y la guerra son ejemplos interesantes de explorar en este sentido, y se puede pensar en la necesaria coexistencia de núcleos de emociones contradictorias en las comunidades más complejas. Es importante también recordar que la clase social y el género jugarán, sin duda, un papel determinante en la aceptación social y en la 'puesta en escena' de las emociones, en cualquier contexto cultural ${ }^{10}$.

Emotions"en Passions in Context 1, 2010, http://www.passionsincontext.de/index.php?id=557 (última visita 10.2.2012).

9 El concepto de 'comunidad emocional' resulta particularmente cercano al concepto de 'comunidad textual' (ver Brian Stock, "Textual communities: Judaism, Christianity and the Definitional Problem", en Listening for the Text. On the Uses of the Past, Philadelphia: University of Pennsylvania Press, 1990, pp. 140-158), si consideramos ciertas comunidades religiosas medievales.

10 El pensamiento del ya mencionado Norbert Elias (1897-1990) ha sido muy influyente en la consideración de las emociones en la construcción de las identidades nacionales, si bien muchos de sus planteamientos han sido reiteradamente criticados por los historiadores; para la historia medieval, ver en particular su libro El Proceso Civilizatorio (1939). Por otra parte, si bien Benedict Anderson no menciona el concepto de emoción, éste puede ser relacionado con algunos aspectos del nacimiento y expansión de las 'comunidades imaginadas' propuestas por este autor en su bien conocida obra Imagined Communities. Reflections on the Origin and Spread of Nationalism, London: Verso 2006 (1983). 


\section{DOS CARTAS}

Para dar cuenta de la 'historicidad de las emociones' de manera muy acotada y en el marco de la escritura monástica europea del siglo XII, quiero tomar como ejemplo dos cartas de la religiosa alemana Hildegard de Bingen (1098-1179). Una de ellas, dirigida a la joven religiosa Ricardis von Stade y escrita en 1151, es una carta de doloroso lamento por el abandono de la joven Ricardis, quien dejó el convento dirigido por Hildegard como su priora y, gracias al apoyo de su influyente familia, fue nombrada abadesa en Bassum, cerca de Bremen ${ }^{11}$.

La segunda carta, escrita hacia 1175, fue la respuesta que Hildegard envió a un joven monje, Guibert de Gembloux, con respecto a la naturaleza de sus visiones. De ese importante texto, he elegido los párrafos que se refieren al sentimiento de debilidad y al temor como emoción dominante, y los he asociado, para efectos de mi argumento en este trabajo, con tres breves textos anteriores que pueden ser antecedentes textuales de la experiencia visionaria que la religiosa puso por escrito en esta carta redactada hacia el final de su vida ${ }^{12}$.

Estas dos cartas, junto a aquella dirigida por Hildegard a los prelados de Mainz para defender a su convento de la interdicción que le prohibía el canto durante los oficios litúrgicos, son de las más conocidas y mencionadas en los estudios sobre su obra.

Por lo mismo, mi aporte no será original en cuanto a sus aspectos textuales; en esta nota se trata más bien de una consideración sobre la especificidad de las emociones que se manifiestan en esas cartas y en la necesidad que tenemos de reconocer que nuestra lectura actual está determinada por ciertos supuestos que, en alguna medida, nos dificultan ponernos en el lugar de los destinatarios contemporáneos a la escritura de esos textos medievales.

En primer lugar, es necesario detenerse en el carácter de los destinatarios de este y de otros epistolarios medievales. La primera consideración que tenemos que tomar en cuenta es que los lectores de muchas de las cartas destinadas (nominalmente) a una sola persona fueron, en realidad, múltiples.

11 Hildegardis Bingensis Epistolarium, Lieven Van Acker (ed.). Pars prima, pp. 147-148.

12 Hildegardis Bingensis Epistolarium, Lieven Van Acker (ed.). Pars secunda, pp. 258-265. 
Por otra parte, y en ese mismo sentido, es necesario recordar el carácter público de muchos epistolarios medievales $\mathrm{y}$, en particular, del epistolario de Hildegard: las cartas que leeremos fueron cuidadosamente catalogadas y conservadas por el monje Volmar, quien fuera el secretario de Hildegard hasta el año 1174, poco antes de su muerte. Se trata aquí del epistolario de una autoridad, de una priora, conservado en los archivos de su convento para ser leído - muchas veces en público-como modelo de escritura, y no se trata, por lo mismo, de comunicaciones exclusivamente privadas ${ }^{13}$. El epistolario de Hildegard, como lo ha demostrado bien John van Engen, formó parte importantísima de su 'persona' pública ${ }^{14}$.

Es importante recordar también el estatuto particular que la religiosa reclamó siempre para todos sus escritos con la exclusión -relativa- de su obra científica y médica: sus escritos serían fruto de la inspiración divina, y mencionó específicamente sus cartas como inspiradas por "la luz divina". Por lo tanto, las emociones y los sentimientos que en estas cartas se expresan son, al mismo tiempo, elementos de una 'revelación', y por lo mismo, forman parte de una comunicación a una comunidad de lectores. Se trata, por cierto, de cartas personales pero, al mismo tiempo y como ya hemos mencionado, se trata de cartas para ser leídas en comunidad y para ser comprendidas como manifestaciones de una 'revelación' por los lectores del presente (y del futuro).

Todas estas características nos deberían poner en alerta y nos obligan, a mi parecer, a una suspensión temporal de nuestras orientaciones interpretativas más habituales.

13 Para una perspectiva sobre los géneros literarios en el mundo monástico medieval $\mathrm{y}$, en particular, sobre la importancia de las cartas y su incidencia en la vida monacal, ver Jean Leclercq, O.S.B., "Literary Genres" en The Love of Learning and the Desire for God. A study of Monastic Culture, New York: Fordham University Press 2011 (la edición francesa original es de 1957), pp. 153-190. En relación con las cartas, a su carácter público, así como al cultivo de la amistad epistolar, ver pp. 176-181.

$14 \quad$ Van Engen, John, pp. 375-418. 


\section{CARTA DE HILDEGARD A RICARDIS VON STADE $(1151)^{15}$}

1. Escucha, hija, a tu madre espiritual, que te dice: mi dolor aumenta. El dolor mata la gran confianza y el consuelo que tenía en una persona. Desde ahora, diré: "mejor es refugiarse en el Señor que confiar en magnates". O sea, que el hombre debería mirar hacia el que vive en las alturas sin que amor alguno o falta de confianza le hagan una sombra como la que el etéreo humor de la tierra da por breve tiempo. Quien contempla así a Dios es como el águila que fija su mirada en el sol. Y por eso no debe uno prestar atención a las grandes personas, que se eclipsan igual que se marchita una flor.

2. Yo incumpli esto por el amor de una noble persona. Ahora te digo que siempre que he pecado de este modo, Dios me ha mostrado ese pecado bien con angustias, bien con dolores, y asi ha sucedido ahora por tu causa, como tú misma sabes.

3. Ahora te digo otra vez: ;Ay de mí, madre! ;Ay de mí, hija! ¿Por qué me has abandonado y dejado huérfana? Yo amaba la nobleza de tu talante, tu sabiduría y tu castidad, y tu espiritu y todo tu ser, hasta el punto que muchos me decían. ¿Qué haces?

4. Ahora, que lloren conmigo todos aquellos que sufren un dolor semejante al mío, quienes sintieron un afecto en su corazón y su alma tan grande como el que yo he sentido por ti, por una persona que les fue arrebatada en un instante, como tú lo fuiste para mí.

5. Pero que el ángel de Dios te guie y que el Hijo de Dios te proteja y que la madre de este te guarde. Acuérdate de tu pobre madre Hildegard; que no te abandone la felicidad ${ }^{16}$.

Al leer esta carta, es necesario recordar, en primer lugar, que las referencias bíblicas explícitas e implícitas en el texto acentúan, sin duda, el carácter ejemplar del mensaje personal. Como se ha estudiado para otros conocidos epistolarios medievales, especialmente el de Abelardo y Eloísa, el llamado

15 Ver el apartado que Peter Dronke dedica a la relación con Ricardis y a la carta que aquí comentamos, en el capítulo dedicado a la escritura de Hildegard de Bingen en su libro Las Escritoras de la Edad Media, Barcelona, pp. 200-277.

16 Hildegardis Bingensis Epistolarium, pars prima, Ep. LXIV, 1991 (pp. 147-148). Cito la traducción castellana de la obra de Peter Dronke, Las Escritoras de la Edad Media, pp. 217-218. Corrijo el párrafo n. ${ }^{\circ} 3$ de acuerdo a la edición crítica de L. Van Acker, p. 147: "Nunc iterum dico: Heu me, mater, heu me, filia, quare me dereliquisti sicut orphanam?". 
'pensamiento figural' o 'tipológico' ${ }^{17}$ es fundamental para la comprensión de la autorrepresentación de los 'autores' y de la lectura por parte de los destinatarios de las cartas ${ }^{18}$.

El 'pensamiento figural' que permea estos escritos cercanos a la autobiografía permitió a sus autores relacionar creativamente las situaciones vividas por los personajes bíblicos con las situaciones cotidianas vividas por ellos mismos. Los personajes del Antiguo Testamento se convierten así en 'figuras' o 'tipos' que culminan en el Nuevo Testamento o que se actualizan en el presente de la persona que se compara con ellos. Podemos afirmar que, en el contexto histórico medieval, esta relación con las 'figuras' bíblicas le presta densidad a lo vivido en el presente y permite su comprensión. La idea de "figura", fundamental para la hermenéutica de las Escrituras, se hace también fundamento e instrumento de comprensión para otras escrituras, y de manera privilegiada, para aquellas cercanas a la biografía y la autobiografía.

Así por ejemplo, la carta dirigida a Ricardis se inicia con las palabras "Audi mi, filia", "Escúchame, hija". De acuerdo a Peter Dronke (p. 218) esas palabras recuerdan un versículo del salmo 44 de la Vulgata que la misma Ricardis y los otros lectores de esta carta recordarían bien:

\section{"Escucha, hija, mira y pon atento oído, \\ Olvida a tu pueblo y la casa de tu padre, \\ $Y$ el rey se prendará de tu belleza" (vv. 11-12) ${ }^{19}$}

El mensaje implícito en esos versículos del salmo (del cual solo es necesario mencionar las primeras palabras, porque tanto Ricardis como todos los

17 Para un estudio en profundidad del pensamiento figural, ver Friedrich Ohly, Sensus Spiritualis: Studies in Medieval Significs and the Philology of Culture, Chicago: University of Chicago Press 2005; en especial, ver el cap. 2, "Typology as a Form of Historical Thought", pp. 31-67. En nuestro medio es bien conocida la breve y notable síntesis de Erich Auerbach, Figura, Madrid: Trotta, 1998.

18 Un estudio polémico y sugerente sobre las cartas de Abelardo y Eloísa se encuentra en Constant Mews, The Lost Love Letters of Heloise and Abelard. Perceptions of Dialogue in Twelfth-Century France. New York \& Houndsmills, Basingstoke: Palgrave, 1999. En el ya mencionado libro de Peter Dronke, Las Escritoras de la Edad Media, es igualmente importante el estudio de la retórica en estas cartas, que Dronke atribuye, en definitiva, a la autoría de la propia Eloísa, pp. 152-194.

19 Ps (44) 45: 11-12 en la versión de Biblia de Jerusalén, Bilbao: Desclée de Brouwer, pp. 754-5. 
destinatarios virtuales de esta carta debieron conocer muy bien los textos de los salmos) se hará más explícito en relación con el contexto de la partida de Ricardis. La acusación de Hildegard es que ésta se ha dejado llevar por la ambición y la presión de su familia al aceptar salir de Bingen y ser nombrada abadesa en Bassum hacia 1151, poco antes de su muerte a los 28 años; tal como lo veremos registrado muchos años más tarde en los fragmentos autobiográficos insertos en su Vita, Hildegard recuerda en duros términos la decisión de Ricardis de alejarse de su convento de Bingen ${ }^{20}$.

El ataque a la familia de Ricardis -y también a ella misma- se hace explícito en las palabras que siguen: "El dolor mata la gran confianza y el consuelo que tenía en una persona. Desde ahora, diré: "mejor es refugiarse en el Señor que confiar en los magnates". La referencia a las Escrituras (“Bonum est sperare in Domino / Quam sperare in princibus", Salmo 117: 9), es totalmente pertinente, puesto que la familia von Stade fue de las más influyentes en el entorno de Hildegard ${ }^{21}$. La recriminación tuvo, sin duda, una densidad textual especial para los lectores contemporáneos gracias a esta referencia bíblica; la expresión textual de la ira y el dolor nos recuerda, por otra parte, el carácter ritual y performativo de estas mismas emociones en el ámbito de la vida pública medieval ${ }^{22}$.

$20 \quad$ Hildegard recibió la noticia de la muerte de Ricardis en una carta escrita por Hartwig von Stade, obispo de Bremen y hermano de la joven religiosa; éste le participa de los deseos de Ricardis, expresados por ella antes de morir, de haber regresado al convento en Bingen y, por su parte, Hildegard responde con una carta en la que reitera su relación con Ricardis (madre e hija suya a la vez) y recuerda la belleza y la nobleza de la joven, afirmando que Dios la amó más que el mundo y, por esa razón, se la llevó consigo. La dureza de la correspondencia previa entre Hildegard y Hartwig quedó así superada, de alguna manera, por el dolor compartido ante la muerte de Ricardis. Ver parte de la correspondencia relacionada con el alejamiento de Ricardis en Hildegardis Bingensis Epistolarium, pars prima, Ep. XII, XIII, XIIIr (pp. 27-31).

21 Sobre el control de la emoción de la ira, las acusaciones y las maldiciones en el mundo monástico medieval, ver Lester K. Little, "Anger in Monastic Curses", en Barbara Rosenwein, ed.: Anger's Past. The social uses of an emotion in the Middle Ages, pp. 9-35.

22 Así lo han desarrollado autores como Gerd Althoffen sus estudios sobre la comunicación social de las emociones en la Alemania medieval. Ver Althoff, Gerd, "Aufgefürhte Gefühle. Die Rolle der Emotionen in der Öffentlichen Rituale des Mittelalters" en Passions in Context 1, 2010, http://www.passionsincontext.de/index.php?id=546 (última visita 10.2.2012). Ver también el artículo del mismo Gerd Althoff, "Ira regis: Prolegomena to a History of Royal Anger” en Barbara Rosenwein, Anger's Past, pp. 59-74. Sobre el tema de la ira en el mundo aristocrático, ver asimismo Stephen D. White, "The Politics of Anger" en Anger's Past, 
En esta carta encontramos una recriminación explícita, como hemos descrito, pero también y por sobre todo, un planctus, un lamento por el abandono, un lamento doliente que se puede asimilar a las innumerables voces medievales que lamentan el abandono de un amante, y que encontramos sobre todo en la lírica. Las referencias a Ricardis que leemos en las frases "Yo incumplí eso por amor a una noble persona" y, más adelante, "Yo amaba la nobleza de tu talante, tu sabiduría y tu castidad, y tu espiritu y todo tu ser, hasta el punto que muchos me decían. ¿Qué haces? "23, deben ser leídas en el contexto de la tradición epistolar y de la valoración de las virtudes.

Por otra parte, y como sucede con otros epistolarios medievales ${ }^{24}$, es necesario asumir al mismo tiempo la dificultad de su comprensión, dado el contexto cultural y social en el que el culto a la amistad y al amor son parte de las relaciones de poder y no solamente de afecto personal, como las ha explorado, entre muchos otros, C. Stephen Jaeger, en una obra polémica y sugerente sobre los discursos amorosos medievales, particularmente en los epistolarios ${ }^{25}$.

Como ya hemos afirmado, en esa tradición son importantes las referencias bíblicas, como la frase "Escucha, hija" que inicia la epístola; pero sobre todo, y más audazmente todavía, nos encontramos con un par de referencias al lamento de Cristo en la Cruz por su soledad y por el abandono de su Padre. Hildegard se acerca aquí 'figuralmente' a Cristo en su abandono, para lamentar el abandono de Ricardis, especialmente en el lamento que culmina con la frase en la que se entrelazan las identidades de la madre y la hija, de Hildegard y de Ricardis: "¡Ay de mí, madre! ¡Ay de mí, hija! ¿Por qué me has abandonado $y$ dejado huérfana?" No es imposible escuchar aquí un eco de la frase de Cristo en la Cruz: "Padre mío, ¿Por qué me has abandonado? Mt 27: 46.

pp. 127-152. Para las representaciones de la ira en el mundo campesino, ver Paul Freedman, "Peasant Anger in the Late Middle Ages" en Anger's Past, pp. 171-188.

$23 \quad$ En el texto latino original leemos: "Hoc transgressa sum propter amorem nobilis hominis", Hildegardis Bingensis Epistolarium, Pars Prima, Ep. LXIV p. 147, 1. 9. y poco más adelante: "Amaui nobilitatem morum tuorum, et saptientiam et castitatem, et tuam animam et omnen uitam tuam, ita quod multi dixerunt: Quid facis?", Hildegardis Bingensis Epistolarium, Pars Prima, p. 147, 1. 15-17.

${ }_{24} \quad$ Ver, por ejemplo, F.C. Gardiner, The Pilgrimage of Desire. A Study of Theme and Genre in Medieval Literature, Leiden: Brill 1971, esp. el capítulo II, “Letters" pp. 53-85.

25 C. Stephen Jaeger, Ennobling Love. In Search of a Lost Sensibility, Philadelphia: University of Pennsylvania Press, 1999. Ver, por ejemplo, el capítulo 1, "Problems of Reading the Language of passionate Friendship", pp. 11-26. 
La asociación con la pasión de Cristo es sin duda más explícita en la frase "Ahora, que lloren conmigo todos aquellos que sufren un dolor semejante al mio", que está presente en la liturgia del Viernes Santo y que proviene de las Lamentaciones de Jeremías: "Oh vosotros los que pasáis por el camino, prestad atención y ved si existe dolor semejante al mío" (Jeremías 1:12).

Después de este clímax, la carta termina con una oración y una petición para Ricardis: Hildegard espera ser recordada por la joven religiosa, a quien envía asimismo deseos de felicidad. Como ya hemos mencionado, Ricardis moriría poco tiempo después de su partida a la abadía de Bassum, a la edad de 28 años.

Entre los materiales autobiográficos - de escritura tardía- que el hagiógrafo Theodrich von Echternach inserta en su Vita Sanctae Hildegardis Virginis, encontramos el siguiente párrafo que sin duda nos permite una visión más completa del 'registro' que Hildegard quiso dejar de su amistad con Ricardis y del destino de ésta:

"Pero Dios no quiso que [yo] permaneciera siempre en completa seguridad....C]uando estaba escribiendo el libro Scivias, tenía en pleno amor (plena karitate) a una monja noble, la hija de la ya citada marquesa, como Pablo a Timoteo. Se había unido a mi en todo por medio de una amorosa amistad (diligenti amicitia), compartiendo conmigo los sufrimientos hasta que terminara aquel libro. Pero debido a su distinguido linaje se inclinó por un puesto más elevado y quiso ser nombrada madre de un importante monasterio, lo que ambicionaba no tanto según Dios sino según el honor del siglo. Después de que se hubiera trasladado a un lugar alejado de nosotras, y se hubiera alejado de mí, perdió muy pronto la vida presente con el nombre de su dignidad" 26 .

\section{CARTA A GUIBERT DE GEMBLOUX (1175)}

El segundo texto al que quiero referirme es un pasaje de la carta que Hildegard escribió a Guibert de Gembloux, hacia el final de su vida, en el año 1175, en la que se resume de manera notable su experiencia visionaria. 
... 'Oh fiel servidor, yo, pobrecita forma de mujer, te digo una vez más estas palabras en verdadera visión: si a Dios le pluguiera elevar tanto mi cuerpo como mi alma en esta visión, no retrocedería el temor de la mente y de mi corazón, pues sé que soy humana, por mucho que fuera encerrada desde mi infancia'.(...) ' $¿ Y$ de dónde vendría esto, si yo no me conociera en mi pobreza? Dios obra alli donde quiere para la gloria de su nombre y no del hombre terreno. Yo siempre tengo un tembloroso temor, pues no sé en mí ninguna seguridad de la posibilidad que sea. Pero tiendo mis manos a Dios y El me sostiene, como una pluma que carece de toda gravedad de fuerzas y se deja llevar por el viento'. Carta a Guibert de Gembloux (1175) ${ }^{27}$.

En este estudio no me referiré a la muy conocida descripción de sus visiones, sino a su autorrepresentación como una pluma frágil llevada por el viento y expuesta al tembloroso temor, una emoción que reiteradamente aparece en la escritura de Hildegard en conexión justamente con su experiencia visionaria y que aparece ligada frecuentemente a la virtud de la humildad. En su primer libro visionario, el Scivias, compuesto entre 1141 y 1151, encontramos ya la presencia de esta imagen poderosa: "Y escuché a Aquel que estaba sentado en el trono diciéndome: 'Escribe lo que ves y oyes'. (...)Y con la ciencia de la visión volví a responder: 'En lo hondo de mi alma me veo como ceniza de ceniza inmunda, polvo del trigo que el viento se lleva; aquí estoy, pues, sentada temblando cual pluma en la penumbra..." (Scivias 3,1$)^{28}$.

Por otra parte, en las cartas que Hildegard de Bingen envió al papa Eugenio III (ca. 1148-1149) y al maestro de teología Odo de Soissons (1147-1148), encontramos dos breves relatos muy similares entre sí y que tienen, a nuestro parecer, un carácter demostrativo importante; en ellos podemos percibir cuál es la imagen de sí misma que Hildegard quiso transmitir a estos dos destinatarios de sus cartas al inicio de sus trabajos de composición y registro de su experiencia visionaria oficialmente admitida por la jerarquía eclesiástica.

27 Hildegardis Bingensis Epistolarium, pars secunda, Ep. CIIIr, p. 258-262 (p. 260) La versión castellana de todos los párrafos citados es de Victoria Cirlot, Hildegard de Bingen. Vida y Visiones, (pp. 164-169), pp. 165-6.

28 Hildegardis Bingensis Scivias. ed. Adelgundis Führkötter \& Angela Carlevaris, CC CM, XLII1 y XLIII A, Turnholt: Brepols, 1978, (p. 329); (traducción revisada de la versión castellana de Scivias, Madrid: Trotta 1999, (A. Castro y M. Castro, traductores). 
I. ... 'Sin embargo, tú, padre de los peregrinos, oye a Aquel que es: un rey muy poderoso reinaba en su palacio y ante él tenía grandes columnas ceñidas por cinturones de oro y adornadas con gran profusión de perlas y piedras preciosas. Pero a aquel rey le plugo tocar una pequeña pluma que volaba milagrosamente. Y un fuerte viento la sostuvo para que no desfalleciera (Carta a Eugenio III, $1148-1149 ?)^{29}$

\section{en mí. \\ ... 'Pero yo tiemblo mucho debido a la humilde forma que hay}

'Oye ahora: un rey estaba sentado en su trono y erigió ante él altas y bellas columnas muy ornamentadas. Los ornamentos eran de marfil y las columnas llevaban con gran honor todos los trajes del rey y alli los mostraban. Entonces al rey le plugo levantar del suelo una pequeña pluma y le ordenó que volara como él quisiera. Pero la pluma no vuela por sí misma, sino que el aire la lleva. Así, yo no estoy impregnada por el conocimiento humano ni por potentes fuerzas, ni tampoco reboso de salud corporal, sino que sólo consisto en la ayuda de Dios'(Carta a Odo de Soissons, 1148-1149) ${ }^{30}$.

El tembloroso temor será pues, en esta lectura, una condición de la actividad y de la experiencia visionaria de Hildegard y encontramos testimonios similares de la expresión de esta emoción en las cartas del epistolario a lo largo de varias décadas: la pequeña pluma que, sin voluntad ni fuerza propias, vuela en el espacio, la preferida por el señor, será también la que registre la experiencia visionaria, la que realice la escritura que se le encomienda. Por lo mismo, no es posible pensar que se trata aquí de un temor habitual frente a un dolor o un acontecimiento que sucederá en el futuro. Se trata, sin duda, del timor dei, del temor religioso ante lo 'numinoso' que describió Rudolf Otto en su clásica obra $L o$ santo ${ }^{31}$; se trata más bien del asombro, el respeto y el amor ante lo sagrado, ante el misterio tremendo y fascinante al mismo tiempo.

29 Hildegardis Bingensis Epistolarium, pars prima, Ep. II, (pp. 7-8); trad. Cirlot, Vida y Visiones, pp. 127-8.

30 Hildegardis Bingensis Epistolarium, pars prima, Ep. XLr, pp. 103-5; trad. Cirlot, Vida y Visiones, p. 132.

31 Rudolf Otto: Lo Santo. Lo racional y lo irracional en la Idea de Dios, (Das Heilige, 1917). 


\section{CONCLUSIONES}

Las cartas que hemos escogido para describir las emociones en el epistolario de Hildegard de Bingen nos muestran que tanto el dolor por la pérdida de Ricardis, así como el tembloroso temor ante las visiones fueron fundamentales para la experiencia personal de Hildegard, tanto en el terreno de las relaciones personales como en el terreno de su relación con Dios, específicamente en su experiencia profética y visionaria.

Por otra parte, la elaboración de estas emociones y sentimientos en la escritura monástica permanecerá sin embargo inaccesible para nosotros si no tenemos en cuenta su historicidad, las condiciones y la comunidad 'emocional' y 'textual' en la que esta escritura pudo surgir. Como hemos visto, la escritura epistolar de Hildegard está plenamente enraizada en los presupuestos del pensamiento figural y asume, por otra parte, la fuerte afectividad de la tradición epistolar de las mujeres letradas medievales, herederas, como Eloísa en su correspondencia con Abelardo, de los ejercicios epistolares en latín de las mujeres letradas de la Alta Edad Media ${ }^{32}$, así como de las (ficticias) cartas de amor que encontramos en las Heroidas de Ovidio. Finalmente, y esto es una característica que no podemos olvidar al leer estas cartas de dolor, de amor, así como de temor religioso, es que fueron escritas como modelos, tanto de escritura como de experiencia monásticas y en ese sentido, se puede hablar con propiedad de su carácter público; fueron escritas para sus destinatarios directos, para Ricardis y para Guibert -así como para Eugenio III y Odo de Soissons-, pero también para una cierta comunidad de lectores; gracias a su registro, somos también nosotros partícipes de estos testimonios, como lectores y lectoras de este siglo.

\section{BIBLIOGRAFÍA}

Cirlot, Victoria (ed.). Hildegard von Bingen. Vida y Visiones. Madrid: Siruela, 1997.

Dronke, Peter. Las Escritoras de la Edad Media. Barcelona: Crítica, 1994.

Führkötter Adelgundis y Angela Carlevaris (eds.). Hildegardis Bingensis Scivias. CC CM, XLII1 y XLIII A, Turnholt: Brepols, 1978. 329.

Knuutila, Simo. Emotions in Ancient and Medieval Philosophy. Oxford: Clarendon Press, 2004.

32 Para un estudio de las mujeres letradas y la lírica latina medieval, ver Peter Dronke, Medieval Latin and the Rise of the European Love-Lyric, 2 vols. Oxford: Clarendon Press, 1965-1966. 
Otto, Rudolf. Lo Santo. Lo racional y lo irracional en la Idea de Dios. Madrid: Alianza, 1980 (Das Heilige, 1917).

Rosenwein, Barbara (ed.). Anger's Past. The Social Uses of an Emotion in the Middle Ages. Ithaca \& London: Cornell University Press, 1998.

Rosenwein, Barbara. "Worrying about Emotions in History". The American Historical Review vol 107.3 (June 2002): 281-245.

Emotional Communities in the Early Middle Ages. Ithaca \& London: Cornell University Press, 2006.

Spinoza, Baruch. Ética demostrada según el orden geométrico. Vidal Peña (ed.). Madrid: Editora Nacional /Ediciones Orbis, 1980.

Theodericus Epternacensis (Theodorich von Echternach). Vita Sanctae Hildegardis Virginis, Monika Klaes (ed.). CC MM, CXXVI, Turnholt: Brepols, 1993.

Van Engen, John. "Letters and the Public Persona of Hildegard von Bingen". Hildegard von Bingen in Ihrem Historischen Umfeld. Alfred Haverkamp (ed.). Mainz: Philipp von Zabern, 2000. 375-418.

Van Acker, Lieven (ed.). Hildegardis Bingensis Epistolarium. CC CM, XCI. pars prima. Tournhout: Brepols, 1991; pars secunda, CC CM, XCI A, 1993. 